\title{
Glycosylated Haemoglobin in Children with Insulin-dependent Diabetes Mellitus
}

\author{
D. Daneman, Eva Tsalikian, Fay Hengstenberg, Dorothy J. Becker, and A. L. Drash \\ Department of Pediatrics, Children's Hospital of Pittsburgh and University of Pittsburgh, Pittsburgh, Pennsylvania, USA
}

Summary. Glycosylated haemoglobin $\left(\mathrm{HbA}_{1}\right)$ was measured serially by microcolumn chromatography in 38 children with newly diagnosed insulin-dependent diabetes. Initial $\mathrm{HbA}_{1}$ levels of $13.6 \pm 0.5 \%$ fell significantly from day 0 (prior to therapy) both to day $1(1.6 \pm 0.2 \%$ decrease $)$ and to day $3-5(2.6 \pm 0.4 \%$ decrease) $(\mathrm{p}<0.001)$. This drop correlated closely with changes in blood glucose $(p<0.001)$, less closely and inversely with plasma bicarbonate levels ( $p<0.01$ ), but not with prior duration of symptoms or changes in serum cholesterol and triglyceride concentrations. $\mathrm{HbA}_{1}$ levels reached a nadir of $8.2 \pm$ $0.3 \% 3$ weeks to 6 months after diagnosis, and correlated with decreasing insulin dosage $(\mathrm{p}<0.001)$. $\mathrm{HbA}_{1}$ levels rose again to $11.4 \pm 0.5 \%$ in 21 patients followed for more than 3-6 months. Our results indicate that (1) $\mathrm{HbA}_{1}$ levels change rapidly during initial stabilization of insulin-dependent diabetes suggesting that glycosylation may not be entirely irreversible, and (2) $\mathrm{HbA}_{1}$ levels are consistent with clinical assessment of control during remission and postremission phases.

Key words: Insulin-dependent, diabetes mellitus, glycosylated haemoglobin, blood glucose, serum triglycerides, serum cholesterol, insulin dose.

Glycosylation of haemoglobin is thought to be a posttranscriptional reaction that is slow, non-enzymatic and largely irreversible $[1,2]$. In patients with diabetes mellitus glycosylated haemoglobin $\left(\mathrm{HbA}_{1}\right)$ levels are significantly elevated and are felt to reflect fairly accurately the integrated glucose concentrations over the previous 2 months [3-7]. However, some workers report poor correlation between clinical ratings of diabetic control and $\mathrm{HbA}_{1}$ levels, allow- ing only separation of excellently and very badly controlled diabetics $[8,9]$. Some recent data suggests that part of the $\mathrm{HbA}_{1}$ fraction is formed by a fast reversible process $[9,10]$. Therefore, acute swings in blood glucose, a common finding in diabetics, could produce changes in $\mathrm{HbA}_{1}$ and thereby invalidate the assumption that $\mathrm{HbA}_{1}$ levels represent long-term control.

Our study was designed to assess $\mathrm{HbA}_{1}$ levels at frequent intervals in children with newly diagnosed insulin-dependent diabetes mellitus (IDD) during the initial stabilization and remission phases. This has enabled us to evaluate the degree of variation of $\mathrm{HbA}_{1}$ over a short period.

\section{Patients and Methods}

Thirty-eight children aged 4 to 17 years with newly diagnosed IDD were studied. There were 18 girls and 20 boys. On admission 17 of the patients were ketoacidotic, 13 ketotic only and 8 were neither ketotic nor acidotic. Two of the patients were severely hyperosmolar with only mild to moderate ketoacidosis. The duration of symptoms prior to diagnosis ranged from 2 days to 16 weeks. Two patients had Hashimoto's thyroiditis, one of whom was diagnosed previously and was receiving L-thyroxine $0.1 \mathrm{mg}$ once daily. In the other, hypothyroidism was diagnosed at the time of initial presentation of IDD. A further patient was found to be thyrotoxic at presentation and has subsequently received propylthiouracil. None of the children received blood transfusions at any time.

Blood samples were obtained on admission prior to the administration of insulin (day 0 ) for measurement of blood glucase levels, acid-base and electrolyte balance, serum lipid levels and $\mathrm{HbA}_{1}$. These measurements were repeated on a fasting specimen on the following day (day 1 ), and on days 3 and/or 5 . At each clinic visit thereafter (2-3 weeks, 2-4 months, 6-8 months and 9-12 months) postprandial blood was sampled in all patients for glucose, cholesterol and $\mathrm{HbA}_{1}$ measurements.

$\mathrm{HbA}_{1}$ was measured by column chromatography using the Quik-Sep microcolumn (Isolab Incorporated, Akron, Ohio) in a laboratory with a stable temperature of $23-24^{\circ} \mathrm{C}$. The mean $\mathrm{HbA}_{1}$ of 75 normal children was $6.1 \pm 0.6 \%$ (mean $\pm \mathrm{SD}$ ). Intra-and 


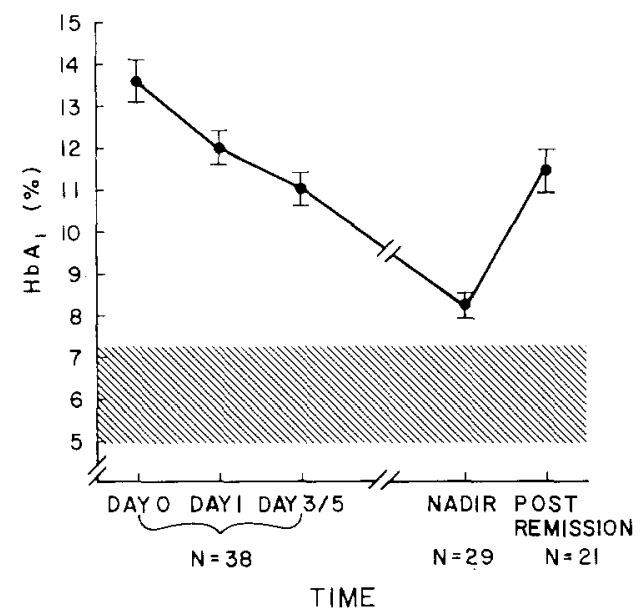

Fig. 1. $\mathrm{HbA}_{1}$ level (mean $\pm \mathrm{SEM}$ ) in 38 study patients during initial hospitalization (days 0-5) and at follow up. The shaded area represents the normal range (mean $\pm 2 \mathrm{~S}$. D.)

interassay coefficients of variation were 2 and $6 \%$ respectively. Glucose was measured by a glucose oxidase method using a YSI (Yellow Springs) analyser. Triglycerides were measured in plasma after extraction by the method of Levy [12]. Cholesterol was measured by the method of Zak [13]. The data were analyzed by simple analysis of variance, Student's t-test for paired means, linear regression analysis and Spearman's rank-order correlation coefficient where applicable. Results are expressed as mean \pm SEM.

\section{Results}

\section{Glycosylated Haemoglobin ( $\left.\mathrm{Hb} \mathrm{A}_{1}\right)$ Levels (Fig. 1)}

At diagnosis the mean $\mathrm{HbA}_{1}$ level was $13.6 \pm 0.5 \%$ which was significantly above normal. There was a highly significant decrease of $\mathrm{HbA}_{1}$ levels of $2.6 \pm$ $0.4 \%$ during the first $3-5$ days in hospital to $11.0 \pm$ $0.4 \%(\mathrm{p}<0.001)$. The fall was most striking from day 0 to day $1(1.6 \pm 0.2 \%)$. The decrease from day 1 to day $3-5$, although significant $(p<0.05)$, was smaller than the initial fall.

In the 29 patients followed more than one month $\mathrm{HbA}_{1}$ reached a nadir of $8.2 \pm 0.3 \%$. This nadir occurred between $2-8$ weeks in 15 patients, 2-4 months in 13 and after 4 months in one. In 25 of these 29 children, $\mathrm{HbA}_{1}$ levels fell below $10 \%$ with 11 values within the normal range. The fall in $\mathrm{HbA}_{1}$ levels correlated closely with decreasing insulin dosage characteristic of the remission phase $(\mathrm{p}<0.0001)$. The mean daily insulin dosage at the time of discharge was $0.72 \pm 0.04 \mathrm{U} / \mathrm{kg}$. At the time of the $\mathrm{HbA}_{1}$ nadir, this had fallen to $0.32 \pm 0.04 \mathrm{U} / \mathrm{kg}$.

In all 21 patients followed for more than 3 to 6 months, $\mathrm{HbA}_{1}$ levels were found to increase again, reaching values of $11.4 \pm 0.5 \%$. This rise was noted

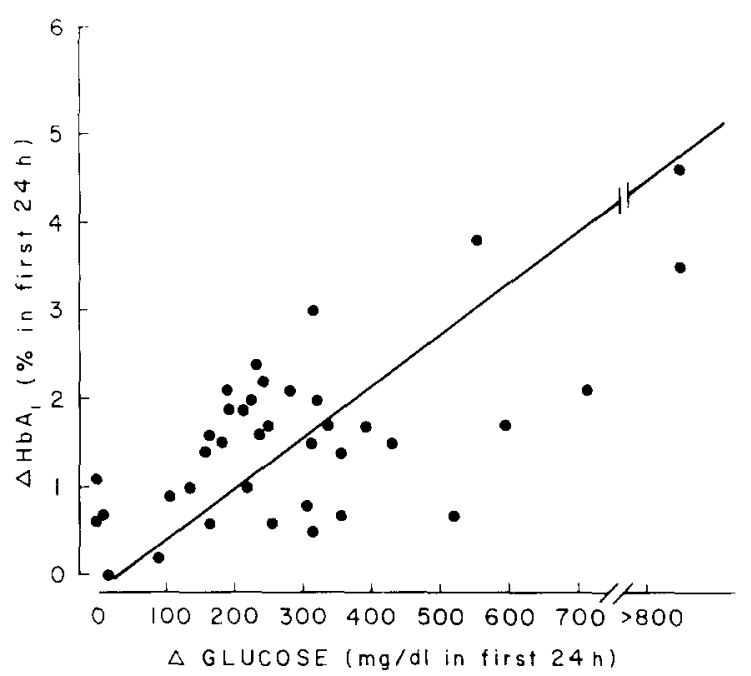

Fig. 2. Significant correlation $(r, 0.65 ; p<0.001)$ between the changes in both $\mathrm{HbA}_{1}$ and glucose levels during the first 24 hours in hospital. Statistical significance estimated by Spearman rankorder correlation coefficient

between 3-6 months in 9 children, 6-9 months in 8 and after 9 months in four. It frequently occurred before or during the period of rapidly increasing insulin dosage. The mean insulin dosage at this time was $0.59 \pm 0.04 \mathrm{U} / \mathrm{kg}$, significantly greater than that at the time of the $\mathrm{HbA}_{1}$ nadir $(\mathrm{p}<0.001)$.

\section{Correlation of $\mathrm{Hb}_{1}$ Levels with Blood Glucose and Lipids}

Figure 2 depicts the highly significant correlation between the changes in both $\mathrm{HbA}_{1}$ and glucose values over the first 24 hours in hospital $(r=0.65, \mathrm{p}<$ 0.001 ). A similar correlation was found between both the initial $\mathrm{HbA}_{1}$ level and its fall and the initial glucose values $(r=0.60, p<0.001$, and $r=0.47$, $\mathrm{p}<0.01$ respectively). There was no correlation between the initial $\mathrm{HbA}_{1}$ or its fall with either the previous duration of symptoms or with changes in serum cholesterol and triglyceride levels during the first five days of therapy. There was an inverse correlation between the fall in $\mathrm{HbA}_{1}$ levels and the initial plasma bicarbonate concentration $(\mathrm{r}=-0.45, \mathrm{p}<$ $0.01)$.

The two children with the highest initial $\mathrm{HbA}_{1}$ levels ( 21.7 and $18.4 \%$ respectively) also showed the largest decrements in $\mathrm{HbA}_{1}$ over the first 3 days in hospital (decrease of 6.1 and $8.8 \%$ respectively). These two patients had in common very severe hyperglycaemia and hyperosmolarity with only mild to moderate ketoacidosis.

Results of tests during the first year after diagnosis, during both the remission and post-remission phases, showed a correlation between $\mathrm{HbA}_{1}$ levels 
and 1-2 hour postprandial blood glucose measurements $(\mathrm{n}=88, \mathrm{r}=0.52, \mathrm{p}<0.001)$. There was a similar correlation between $\mathrm{HbA}_{1}$ levels and $24 \mathrm{~h}$ glycosuria measured in a specimen collected in the week prior to a clinic visit $(n=48, r=0.53, p<$ $0.001)$. There was no correlation between $\mathrm{HbA}_{1}$ levels and serum cholesterol values during this period. Of note is the very significant correlation that existed between $\mathrm{HbA}_{1}$ levels and insulin dosage at each visit $(\mathrm{n}=76, \mathrm{r}=0.52, \mathrm{p}<0.001)$.

\section{Discussion}

These results show that glycosylated haemoglobin is increased in all children with newly diagnosed IDD and correlates with the degree of hyperglycaemia, but not with its duration as assessed by prior symptoms. Using a column method there is a highly significant fall in $\mathrm{HbA}_{1}$ levels during the initial 5 day stabilization phase in hospital particularly during the first 24 hours. This represents a previously unreported finding in newly diagnosed diabetics. Because the degree of hyperglycaemia and decreased bicarbonate concentration are probably related to the severity of the metabolic disorder, their respective correlations with changes in $\mathrm{HbA}_{1}$ levels might simply reflect their interdependence.

The high $\mathrm{HbA}_{1}$ levels at diagnosis confirm previous reports in maturity onset diabetes $[14,15]$ and much smaller groups of children with IDD [16]. In these studies $\mathrm{HbA}_{1}$ levels were not noted to fall significantly although in none were measurements made as frequently as in our study. Fraser et al. [14] found the highest $\mathrm{HbA}_{1}$ concentrations in patients with maturity onset diabetes with glycaemic symptoms of long duration and high plasma glucose concentrations at diagnosis. Ditzel and Kjaergaard [15] reported that a return to normal or near normal values took 25-80 days depending on initial $\mathrm{HbA}_{1}$ levels and degree of control. Our study confirms this latter finding with $\mathrm{HbA}_{1}$ levels reaching a nadir 3 weeks to 6 months after diagnosis. Paulsen and Koury [16] showed raised $\mathrm{HbA}_{1}$ levels in four newly diagnosed children in acidosis that were not altered with correction of acidosis or regulation of the diabetic state over the next $7-10$ days. On the other hand, Karamanos et al. [10] suggested that changes in $\mathrm{HbA}_{1}$ can be found over three to four day intervals in parallel with changes in diabetic control in 10 patients with IDD. Svendsen et al. [9] were able to alter $\mathrm{HbA}_{1}$ levels acutely both in vivo, by means of control of blood glucose by an artificial pancreas (GCIIS, Biostator), and in vitro, by incubation of whole blood in saline with and without added glucose. Also using the GCIIS, Bolli et al. [11] found similar acute falls in $\mathrm{HbA}_{1}$ levels during a 3 day period in 11 patients with IDD in varying degrees of metabolic control.

The reason for the fall in $\mathrm{HbA}_{1}$ remains uncertain. In patients with diabetes mellitus, glycosylation of haemoglobin occurs predominantly at the N-terminus of the $\beta$-chain to produce the two-to threefold elevations of $\mathrm{HbA}_{1 \mathrm{c}}$ [2]. This reaction occurs first by means of a Schiff base that undergoes an Amadori rearrangement forming an essentially irreversible ketoamine linkage. The first step, the aldimine modification, may be easily reversible. In addition, glucose may bind to other residues in both $\alpha$ and $\beta$ chains. These reactions do not produce chromatographically separable minor components $[1,5]$. It has been suggested that glucose may bind non-specifically and reversibly to these sites [5]. This may account for the highly significant reversible component noted in our column study which was closely correlated with changes in blood glucose levels.

Our findings in children with IDD confirm the fall of $\mathrm{HbA}_{1}$ levels during the weeks to months following institution of insulin therapy reported in adult diabetics $[14,15]$. In children the decreasing $\mathrm{HbA}_{1}$ reflects the improved carbohydrate tolerance noted during the honeymoon phase when insulin dosage decreases markedly and stability is relatively easily achieved. Increasing $\mathrm{HbA}_{1}$ levels noted at the end of the remission phase in our patients followed for longer than three to six months are consistent with the declining carbohydrate tolerance as demonstrated by rising insulin requirements. This suggests that a rising $\mathrm{HbA}_{1}$ may serve as a signal to further increase insulin requirement before the patient is symptomatically hyperglycaemic.

After stabilization the close correlation between $\mathrm{HbA}_{1}$ levels with random blood glucose values and 24 hour glycosuria, provides further evidence that $\mathrm{HbA}_{1}$ estimation is a valuable adjunct in the assessment of diabetic control.

This study highlights the role of $\mathrm{HbA}_{1}$ in newly diagnosed diabetic children and should provide further impetus to the better characterization of the glycosylation process.

Acknowledgements. This work was supported by the National Institutes of Health (Clinical Research Center Grant 5M01RR00084-17) and by the Renzichausen Grant. Appreciation is expressed to Janis Gordon for typing and secretarial assistance.

\section{References}

1. Bunn HF (1978) Glycosylated hemoglobins and diabetes mellitus. Resident and Staff Physician, p 53-57

2. Bunn HF, Haney DN, Kamin S, Gabbay KH, Gallop PM (1976) The biosynthesis of human hemoglobin $\mathrm{A}_{1 \mathrm{c}}$. J Clin Invest 57: 1652-1659 
3. Gabbay KH, Hasty K, Breslow JL, Ellison RC, Bunn HF, Gallop PM (1977) Glycosylated hemoglobins and long-term blood glucose control in diabetes mellitus. J Clin Endocrinol Metab 44: 859-864

4. Gonen B, Rochman H, Rubenstein AH (1979) Metabolic control in diabetic patients: Assessment by hemoglobin $A_{1}$ values. Metabolism 4 [Suppl 1]: 448-452

5. Gonen B, Rubenstein AH (1978) Hemoglobin $A_{1}$ and diabetes mellitus. Diabetologia 15: $1-8$

6. Koenig RJ, Peterson CM, Jones RL, Saudek C, Lehrman M, Cerami A (1976) Correlation of glucose regulation and hemoglobin $A_{1 c}$ in diabetes mellitus. N Engl J Med 295: $417-420$

7. Tze WJ, Thompson KH, Leichter J (1978) $\mathrm{HbA}_{1 \mathbf{c}}-$ an indicator of diabetic control. J Pediatr 93: 13-16

8. Gonen B, Rubenstein AH, Rochman H, Tanega SP, Horwitz DL (1977) Hemoglobin $A_{1}$ : An indicator of the metabolic control of diabetic patients. Lancet II: 734-736

9. Svendsen PA, Christiansen JS, Welinder B, Nerup J (1979) Fast glycosylation of haemoglobin. Lancet: 603

10. Karamanos B, Christacopoulos P, Zachariou N, Korkolis S (1977) Rapid changes of the haemoglobin $A_{1 c}$ fraction following alterations of diabetic control. Diabetologia 13: $406 \mathrm{~A}$

11. Bolli G, Cartechini MG, Compagnucci P, Santeusanio F, Massi-Benedetti M, Calabrese G, Puxeddu A, Brunetti $P$ (1980) Modification of glycosylated haemoglobin concentra- tion during artificial encocrine pancreas treatment of diabetes. Diabetologia 18: 1-6

12. Levy AL (1971) Measurement of triglyceride using nonane extraction and colorimetry. In: The clinical pathology of lipids. Institute of Clinical Science, Washington D. C., p IX

13. Zak B (1957) A simple rapid microtechnique of serum total cholesterol. Am J Clin Pathol 27: 583

14. Fraser DM, Smith AF, Gray RS, Borsey DQ, Sinclair ME, Clarke BF, Duncan LJP (1979) Glycosylated haemoglobin concentrations in newly diagnosed diabetics before and during treatment. Br Med J I: 979-981

15. Ditzel J, Kjaergaard JJ (1979) Haemoglobin $A_{1 c}$ concentrations after initial insulin treatment for newly discovered diabetes. Br Med J I: 741-742

16. Paulsen EP, Koury M (1976) Hemoglobin $A_{1 c}$ levels in insulin-dependent and -independent diabetes mellitus. Diabetes 25: $890-896$

Received: September 6, 1979, and in revised form: June 20, 1980

Allan L. Drash, M. D.

Children's Hospital of Pittsburgh

125 DeSoto Street

Pittsburgh, PA 15213

USA 